\title{
Safety Protocols for Videolaryngoscopy During the COVID-19 Pandemic: A Prospective Review of 196 Cases
}

\author{
Sachin Gandhi ${ }^{1} \cdot$ Subash Bhatta $^{1}$ (C) $\cdot$ Shraddha Jayant Saindani $^{1} \cdot$ Dushyanth Ganesuni $^{1} \cdot$ Asheesh Dora Ghanpur $^{1}$
}

Received: 23 July 2020/Accepted: 27 August 2020/Published online: 31 August 2020

(C) Association of Otolaryngologists of India 2020

\begin{abstract}
To prepare safety protocols for performing videolaryngoscopy (VLS) during COVID-19 pandemic, that would be feasible for patients, hospital and the health care providers. This was a prospective study performed from March 01, 2020 to June 30, 2020. It analyzed the precautions adapted for VLS initially and subsequently describes modifications with the time. The safety protocols are developed considering the safety aspect, the feasibility aspect (due to increase in number of the VLS), and the financial aspect. The VLS was performed with the personal protective equipment (PPE), including the face shield mask and head cover. The PPE was re-used after sterilization with ethylene oxide. For local anesthesia, the oropharynx was sprayed with $15 \%$ xylocaine and nose packed with $4 \%$ xylocaine soaked pledget. Following the VLS, the scope was wiped three times with $80 \%$ alcohol and then immersed in $5.25 \%$ sodium hypochlorite and $0.55 \%$ orthophthalaldehyde for 10 min each. Each VLS was spaced by at least 15 min gap. The endoscopy suite maintained with laminar air flow. It can be concluded that during the COVID-19 pandemic, the VLS must be performed using PPE with proper sterilization of the scope and the endoscopy suite after the procedure. The use of face shield mask and $15 \%$ xylocaine spray into the oropharynx were also highlighted. The financial burden should be minimized by reusing the materials whenever possible.
\end{abstract}

Subash Bhatta

2042subase@gmail.com

1 Department of Laryngology, Deenanath Mangeshkar Hospital and Research Centre, Erandwane, Pune 411004, India
Keywords Videolaryngoscopy · COVID-19 .

Safety protocols

\section{Introduction}

In December of 2019, in Wuhan, China, the Novel Corona virus (COVID-19) epidemic originated and thereafter rapidly spread throughout the world [1-4]. The World Health Organization (WHO) declared the disease as a pandemic on March 11, 2020 [5, 6]. The COVID-19 infection primarily involves the respiratory system, including both the upper and the lower airways [2, 3, 7]. Subsequently, the viral load is found to be the highest in the nasal cavities, nasopharynx, oropharynx, hypopharynx, larynx and the lower airways $[7,8]$. The characteristics of the virus and its transmission route makes the videolaryngoscopy (VLS) a potential medium for spread of the infection. The involvement of the transmucosal upper airway further increases the generation of the aerosols during the VLS [5, 9-11].

The provision has been suggested to perform the VLS only when it is dire emergency, with all the necessary precautions [12-16]. There are studies in the literature conducted to update the knowledge and formulate guidelines to carry out upper and lower gastrointestinal endoscopy safely during the COVID-19 pandemic [9, 17-22]. However, there are no studies that have described the precautions to be followed while conducting the VLS during the COVID-19 pandemic. In this study, a holistic attempt is made to share the experience of planning and logistics over a 4 months period to achieve safe and efficient VLS practice which can be extrapolated during the pandemic outbreak. The ongoing nature of the COVID-19 pandemic and the increase in number of patients visiting 
the hospital, has led to a situation where it is increasingly tough to deny the VLS. The need to perform the VLS, even for the non-emergency cases, is also eminent in near future which will lead to significant rise in the number of VLS. This will lead to need for some firm precautions and safety protocols in place to minimize the risk of spread COVID19 while performing VLS. This study develops a safety protocol to be followed for undertaking the VLS based on the experience and review of the cases, keeping in consideration the increasing number of cases for VLS.

\section{Materials and Methods}

This was a prospective study with an objective to formulate the safety protocols for performing the VLS during the COVID-19 pandemic, that would be feasible for the patients, the hospitals and the health care providers. The protocols to be developed were mainly aimed to cope up with the increasing number of VLS in the coming days. The study includes all the VLS performed from March 01, 2020 to June 30, 2020. The study was carried out in Laryngology Department (E.N.T), Deenanath Mangeshkar Hospital and Research center, Pune, India (referred as 'hospital' from here on). Approval for the study was granted by the Institutional Ethics Committee of the hospital.

The demographic data, age, gender and diagnosis of the patients were recorded in the proforma, which was produced after thorough discussion in the department. The proforma also included the precautions taken during the VLS. It was mandated to mention about the precautions taken during VLS in detail. This study details the descriptive analysis of the precautions adapted initially during the start of the March, 2020, and then explains about the changes that were made with the time till June 30, 2020. The various modifications incorporated in the precaution protocol were explained with the reasoning behind the modifications.

The proforma of all the patients were collected and analyzed every 15 days and discussions were held in the department meeting. In addition to the doctors and paramedical staffs in the department, the personnel from the microbiology department, infectious disease department and the instruments sterilization department were also involved for their expert opinion. The number of the VLS performed in the past 15 days, the protocol followed, the problems faced during the procedure, and the need for any modifications were discussed during the meeting. The new protocol was also developed for precautions to be followed for the next 15 days. The protocols were strictly followed. If any need was felt for the change in between the meetings, a provision was made to discuss with the head of the department and all the other members of the meeting over the phone.

The precautions to be taken were divided into precautions for the patients, precautions for the physician doing the VLS (mentioned as 'physician' from here on), precautions for the person assisting in the VLS (mentioned as 'assistant' from hereon) and other health care workers, and eventually the precautions to avoid the spread of aerosols in the endoscopy suite. An evaluation was also performed about the financial burden that was involved while taking such precautions. The financial burden was evaluated with regards to the burden on the patient and the burden on the hospital. This study shows the changing trend of the precautions for performing the VLS during the time period, taking into consideration the safety aspect, the feasibility aspect (due to increase in number of the VLS), and the financial aspect.

\section{Results}

A total of 196 VLS were included in the study, distributed according to the months and the indications for doing VLS (Fig. 1). The average age of patients undergoing VLS was $43.2 \pm 11.3$ years, of which 128/196 (65.3\%) were male and 68/196 (34.7\%) were female respectively. There were 11 patients of the pediatric age group, with age less than 14 years.

In the first half of March, all the VLS were performed with the use of surgical gown, surgical mask, and gloves for the physician with no provision for time period spacing between the two VLS. The scope used in the VLS was cleaned three times with the $80 \%$ alcohol after use. The oropharynx and nasal cavity were sprayed with $15 \%$ xylocaine spray before performing the VLS. This was, however, changed in the early part of the mid-March when $15 \%$ xylocaine sprays were not used, only nasal cavities were packed with $4 \%$ xylocaine soaked pledgets. The scope was smeared with the $2 \%$ xylocaine jelly before introducing into the nasal cavity.

In the second half of March, the number of the VLS fell down drastically (Fig. 1). The VLS was now only performed for the emergency cases. The physician wore a surgical gown similarly like during the normal times with two layers of gloves and head cap. The use of goggles and N-95 mask was mandated for physician during the VLS. The patient's nose was packed with $4 \%$ xylocaine soaked pledget and the spray was not used. The smallest available scope, the $2.7 \mathrm{~mm}$ flexible scope, was used for all the selected patients. The scope was cleaned with alcohol three times, and then dipped in the $0.55 \%$ ortho-phthalaldehyde (OPA) for at least $15 \mathrm{~min}$. The two VLS were spaced at 


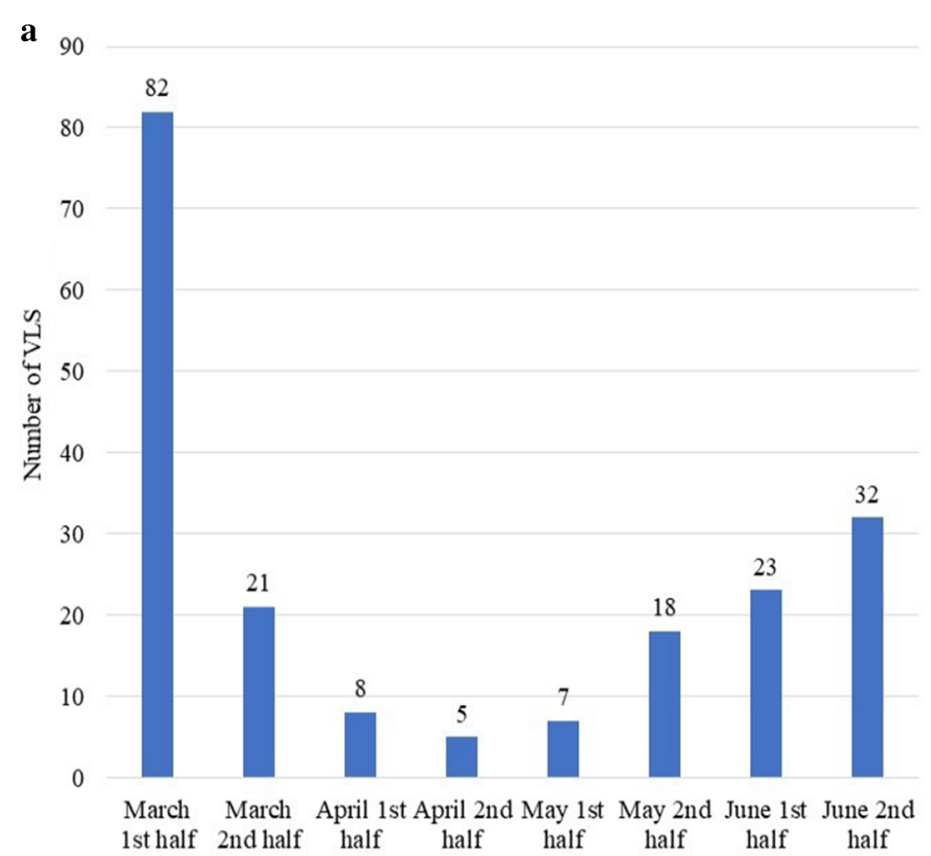

b

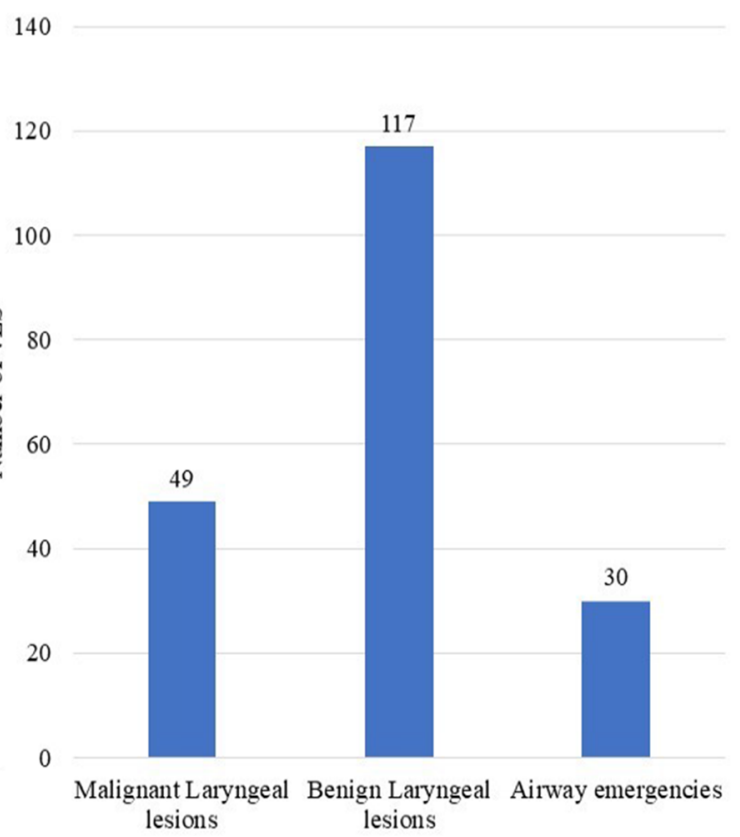

Fig. 1 a VLS performed during different months; b indications for performing VLS; VLS, Videolaryngostroboscopy

least an hour, with the endoscopy suite closed for that time period.

The number of VLS during the April declined even further (Fig. 1). The protocol was made clear and strict by this time. The physician had to change into the in-house dress and had to wear the personal protective equipment (PPE), which includes water proof gown, head cap completely covering the head and the neck, a N 95 face mask, goggles, and leg cover. The patient was also provided with a mask with a hole punched in it (Fig. 2) to pass the scope. The Local anesthesia (LA) was given similarly like it was given during the second half of March. After the procedure, the scope was cleaned with $80 \%$ alcohol three times and then dipped first in the 5.25\% Sodium Hypochlorite solution (NaOCL) and OPA for 10 min each. Endoscopy suite was closed for minimum of $2 \mathrm{~h}$. The VLS was performed in the presence of an assistant, wearing similar PPE as the physician.

The PPE suit was provided by the hospital, along with the N 95 mask. The patients were charged approximately 28-30 USD under the heading infectious disease control. The used PPE were discarded, which added to the already increased load of the hospital waste management.

There was increase in the number of VLS during May (Fig. 1). The hospital changed its protocol, and no longer provided PPE. It was mandatory for the patient to bring the PPE kit. Each patient was asked to bring two PPE kit, for the physician and the assistant. To reduce this to some extent, during the second part of the May, the VLS was performed without the help of the assistant.

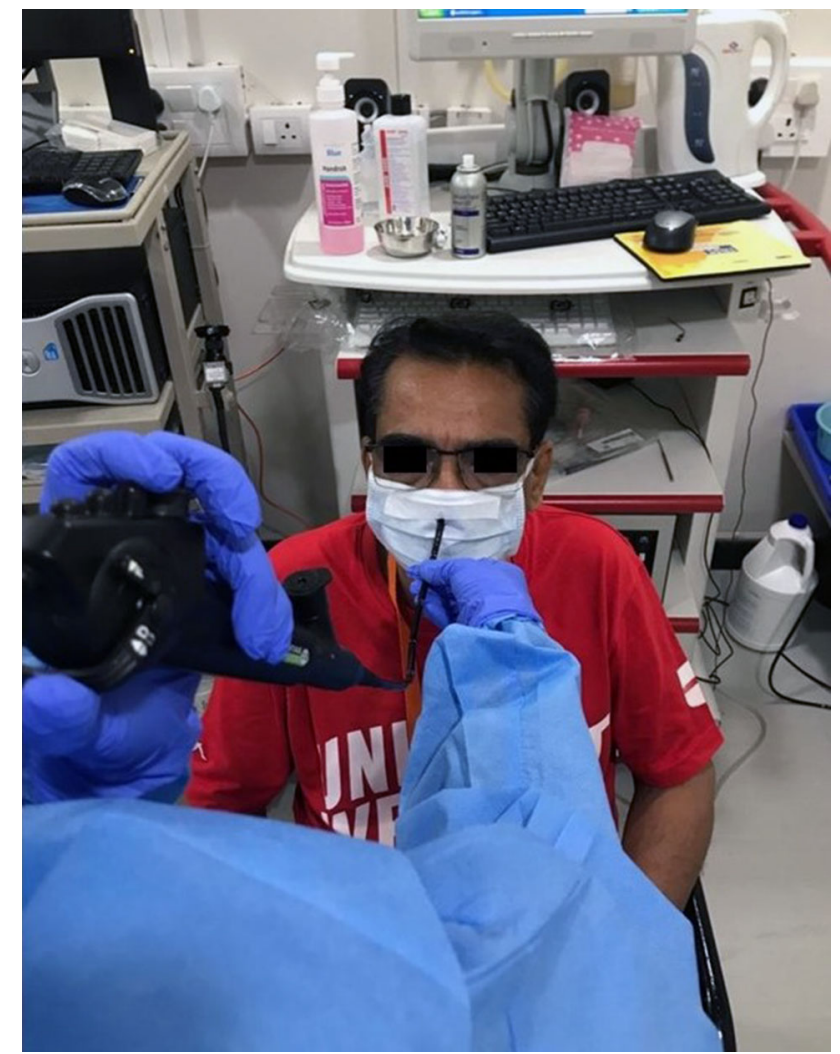

Fig. 2 Hole in the mask for passing the scope

There were many difficulties felt with PPE, such as the excessive fogging with the use of goggles, the sweating inside the PPE suit, and difficulty in communicating with 
the colleagues. The discussion held in the meeting proposed the use of the face shield mask with full head cover (Fig. 3). This led to significant reduction in the fogging, evidenced by the feedback from physician performing the VLS. There was no need to clean the fog with the use of this method, as reported by the physician.

Another problem encountered during the VLS was the coughing or gagging of the patient while passing the scope beyond the nasopharynx, as LA was not used in the oropharynx. Regarding this decision was made to spray the oropharynx with $15 \%$ xylocaine. To support this, comparison was performed by making two groups, consisting 10 patients each. The VLS was performed without spraying the oropharynx and after spraying the oropharynx with $15 \%$ xylocaine in the first and second group respectively. The spraying was undertaken by pulling down the mask of the patient, and immediately replacing it after spraying the oropharynx. This was done in order to contain the aerosol generated during cough, if any, inside the mask. To compare the risk of aerosols generation, the bouts of cough were counted. The first and second group had average of $2.2 \pm 0.83$ and $0.71 \pm 0.18$ bouts of cough per VLS respectively. This difference was significant with $\mathrm{p}$ value of 0.005 on applying independent $t$ test.

There was surge in VLS in June (Fig. 1). The safety protocol for performing VLS was nearly evolved at this stage. A few disadvantages were noticed like the increased economic burden on the patient (patient had to buy PPE kit), that was discarded after VLS. The time gap of $2 \mathrm{~h}$ between the two VLS, creating problem with increasing number of VLS. The decision was made to reuse the PPE kit. The two VLS were spaced by 15 min with the use of laminar flow of air in the endoscopy suite. The used PPE were sterilized with the Ethylene oxide (ETO) and reused.

The impact of the financial burden was also evaluated. The charge for one PPE kit (as per June 2020) was approximately 25-30 USD. This amount was to be bore by the patients for the VLS. In addition to this, the need for its proper disposal was adding to the financial burden on the hospital (approximately 5-6 USD per PPE, as per hospital administration). The reuse of PPE significantly reduced these expenses. The cost to be bore by hospital for recycling and sterilizing the PPE was comparable to the cost bore for their disposal. The cost of reusing of one PPE, when everything was taken into consideration, came out around 8-9 USD. The patients were charged 4-5 USD for every VLS under the heading of infectious disease safety. This amount was used for the replacement of the PPE kit (if required) and to overcome the increased load of sterilization materials being used. The total cost, thus, was reduced from approximately $30-35$ USD to $12-14$ USD (60\% reduction).

The alternate for spraying of the oropharynx was also considered; the use of xylocaine gargle. The patients were
Fig. 3 Use of face shield mask; a face shield mask; $\mathbf{b}$ physician wearing face shield mask with full head and neck cover a

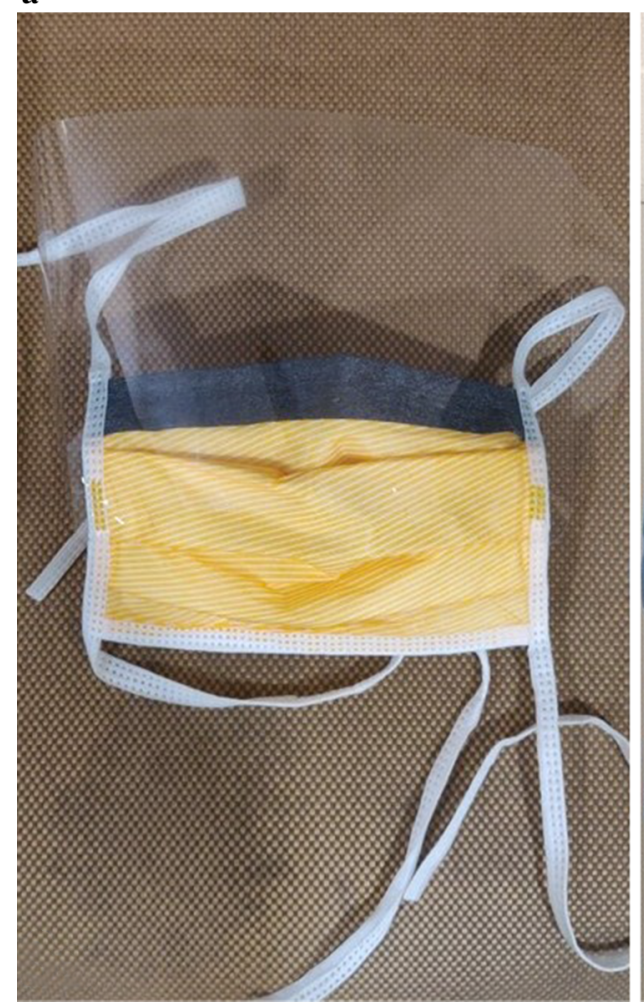

b

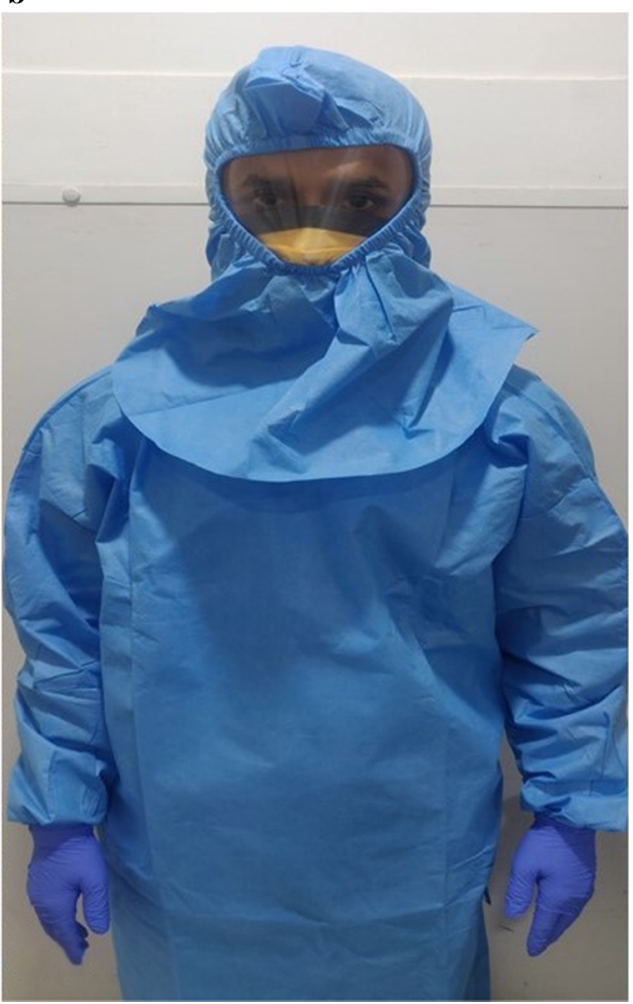


provided with $5 \mathrm{~mL}$ of $4 \%$ xylocaine mixed with $10 \mathrm{ml}$ of water, and were asked to gargle for at least $10 \mathrm{~min}$. The use of xylocaine gargle was done in 10 patients, and it was found that the bouts of cough (mean $0.78 \pm 0.13$ ) were similar to when using $15 \%$ xylocaine spray $(0.71 \pm 0.18)$, with no significant difference on applying independent $t$ test, $p$ value 0.07 .

During this COVID-19 pandemic, the VLS was performed for 11 patients of the pediatric age group. In these patients, $4 \%$ xylocaine soaked pledget were kept in the nasal cavities and scope was impregnated with the $2 \%$ xylocaine jelly, and the spraying was not done. Rest of the precautions were similar as with other patients.

The VLS was performed in three known COVID-19 positive patients, two were having grade III tracheal stenosis and one, transglottic carcinoma obstructing the airway. In addition to usual precautions, the patients were covered in a plastic sheet during the VLS. The LA was given by a pledget soaked in $4 \%$ xylocaine, kept in the nasal cavity, and spray was not used. The tracheoscopy was performed by giving $5 \mathrm{~mL}$ of $4 \%$ xylocaine through the port of the flexible scope. The risk of performing VLS in COVID-19 positive patient came with an opportunity. The secretion from the scope immediately after the VLS was sent for COVID-19 PCR testing (sample 1). The scope was cleaned with $80 \%$ alcohol three times and the wiped off secretions around the scope were sent for COVID-19 PCR testing (sample 2). The sample was sent separately after dipping in NaOCL and OPA (sample 3 and sample 4, respectively). It was found that sample 1 was positive and sample 2, 3 and 4 were negative in all three patients.

\section{Discussion}

The spreading of the COVID-19 virus is maximum from the secretions of the respiratory tract making VLS a high risk factor for the aerosol generation [7, 8]. Out of the total VLS, the 117/196 (59.7\%) were performed for the benign disease, with 82/117 (70.1\%) of them being in March. The high number of the VLS performed in the first half of March was due to lack of any selection criteria set for performing the VLS, and also due to no lockdown being imposed during that time period (lockdown implemented from March 22, 2020). The available information regarding COVID-19 during the early days of pandemic came from limited number of studies [23-26].

The small number of COVID-19 cases and lack of adequate knowledge about COVID-19 during early March were the primary reason behind not having an any definite protection measure for performing VLS in March. The increasing number of COVID-19 cases, along with increasing number of research articles by this time, immensely helped to understand the virus and formulate safety protocol for performing the VLS. The guidelines were set to perform VLS only for emergency cases, suggested by various other studies also [5, 9, 12, 15, 21]. This is evidenced by decrease in number of VLS after March (Fig. 1).

There was lack of definitive data in the literature to suggest the choice of scope for VLS. Among the available limited studies the flexible scope was preferred, as this creates a distance between the physician and the patients, reducing the direct exposure of the physician to the aerosols $[11,15,16,22]$. The rigid scope put the physician in direct exposure to the oral cavity of the patient. This study recommends the use of flexible scope with the smallest size available, with $2.7 \mathrm{~mm}$ diameter scope used in the study. The use of larger scope, with limited use of LA was associated with more discomfort to the patient, resulting in aerosol generation.

The use of PPE was suggested by various studies while doing the VLS [11, 22, 27-30]. This study also recommends the use of PPE, with slight modifications from the standard design. The excessive fogging of goggles was found to be creating hindrance while performing the VLS. The face shield mask along with the full head cover was used instead of the goggles and mask. The protection from the aerosols by using face shield mask and mask with goggles was comparable, in addition the face shield mask provided the advantage of having the significant reduction in fogging.

The use of LA spray has been suggested to produce more aerosols [16, 29, 31, 32]. Accordingly, the LA sprays were not used in the initial days, but after performing a number of VLS it was realized that the patient ought to cough more during the VLS when the oropharynx has not been anaesthetized. This was proven by a comparison done between the two patient groups. On the basis of these findings, the $15 \%$ LA spray was used routinely. Alternatively, this study provides the option to use $4 \%$ xylocaine gargle with equal efficacy in reduction of bouts of cough. The anesthetic effect given by $4 \%$ xylocaine gargle was suitable for performing the VLS [33-35]. However, the risk of aerosols generation during the gargle was found to be more. The washrooms used for gargling was contaminated and required closure for least $1 \mathrm{~h}$ after use. The need for the dedicated isolated washroom and the lack of feasibility of gargle in every patient were the limitations for using the $4 \%$ xylocaine gargle. The study suggests the use of $4 \%$ xylocaine gargle for giving LA whenever a dedicated washroom is available for the VLS patients or proper decontamination of washrooms can be achieved through closures.

The scope was sterilized with $80 \%$ alcohol followed by dipping in both NaOCL and OPA for 10 min each after the VLS. The three positive patient's scope swabs were tested to be negative in PCR test, after cleaning with $80 \%$ alcohol. Since this was a small sample size to extrapolate the 
findings, it gave a fundamental idea. Due to the lack of proper evidence on the use of sterilizing agent, all three of these agents were used. The lipid envelope included in the structure of the COVID-19 makes it very susceptible to the disinfectants such as $62 \%$ to $71 \%$ ethanol, $0.5 \%$ hydrogen peroxide or $5.25 \%$ NaOCL and $0.55 \%$ of OPA [36-41]. The time period for sterilization used in this study was more than the time period suggested by various studies $[37,39,42]$. There was no evidence suggested in literature to show exact time for these sterilizing agents against the COVID-19 virus. All the information available was only the hypothesis based on the properties of COVID-19 virus.

The aerosol spread in the endoscopy suite was reduced by spacing the VLS with at least $15 \mathrm{~min}$. There is no published data describing the exact time required for the aerosols to settle down. The "ENT UK guidance for aerosol generating procedures" suggests that there is no aerosol generation in majority of VLS. The aerosols are generated only when there is cough or sneezing during the VLS, that also will be contained in the facial masks wore by the patients. Thus suggesting no need of prolonged rest period after the procedure [43]. The spacing time used during the initial months was at least $2 \mathrm{~h}$ was due to lack of the guidelines in the literature, which was reduced during the latter months. The negatively pressurized endoscopy suite or the well ventilated endoscopy suite has been recommended by various studies in the literature [16-18, 21, 43]. In cases, when these were not available, laminar air flow inside the endoscopy suite was suggested. The laminar air flow filters both the incoming and outgoing air, and helps reduce the contamination of the air conditioner system.

The financial burden was reduced with the reuse of the PPE by $60 \%$ for a single VLS. The ETO has been suggested to be very suitable for these materials with a good viricidal property $[42,44]$. However, the data is lacking on the effectiveness of ETO with the COVID-19 virus.

The small sample size, short duration and more of the experience-based findings rather than the objective outcomes were the main shortcomings of this study. The limited number of COVID-19 positive patients with the VLS was also one of the limitations of the study, as the actual evidence of efficacy of the protocol was not tested in the positive patients. This study recommends future research in the similar subject matter with increased duration involving larger sample size of the COVID-19 positive patients.

\section{Conclusion}

The study concludes that the VLS being the maximum aerosol generating procedure has to be performed with utmost safety precautions using PPE along with proper sterilization of the scope and the endoscopy suite after the procedure. The study highlights the use of face shield mask to reduce the fogging and also the importance of use of a $15 \%$ LA spray into the oropharynx for performing the VLS. The financial burden to be incurred with the use of these safety precautions should be brought to minimum by reusing the materials whenever possible.

Acknowledgements This research was fully supported by Laryngology Department of Deenanath Mangeshkar Hospital and Research Center. We would like to extend our heartful thanks to all our colleagues from ENT Department of Deenanath Mangeshkar Hospital and Research Center who provided insight and expertise that greatly assisted the research. We would like to thank Dr Gauri Oak, Head of department, Research Department, Deenanath Mangeshkar Hospital and research center and Deevika Joshi, Research Assisstant, Research Department, Deenanath Mangeshkar Hospital and research center for their assistance in the biostatistics, language correction and technical issues.

Funding Research funded by Department of Laryngology (E.N.T.).

\section{Compliance with Ethical Standards}

Conflict of interest There was no conflict of interest.

\section{References}

1. Wu Z, McGoogan JM (2020) Characteristics of and important lessons from the coronavirus disease 2019 (COVID-19) outbreak in China: summary of a report of 72314 cases from the Chinese Center for Disease Control and Prevention. JAMA—J Am Med Assoc 323(2020):1239-1242. https://doi.org/10.1001/jama. 2020.2648

2. Wang D, Hu B, Hu C, Zhu F, Liu X, Zhang J, Wang B, Xiang H, Cheng Z, Xiong Y, Zhao Y, Li Y, Wang X, Peng Z (2020) Clinical characteristics of 138 hospitalized patients with 2019 novel coronavirus-infected pneumonia in Wuhan, China. JAMA—J Am Med Assoc 323(2020):1061-1069. https://doi.org/ 10.1001/jama.2020.1585

3. Lu D, Wang H, Yu R, Yang H, Zhao Y (2020) Integrated infection control strategy to minimize nosocomial infection of coronavirus disease 2019 among ENT healthcare workers. J Hosp Infect 104(2020):454-455. https://doi.org/10.1016/j.jhin.2020. 02.018

4. Coronavirus (COVID-19) events as they happen (n.d.). https://www.who.int/emergencies/diseases/novel-coronavirus2019/events-as-they-happen. Accessed 28 June 2020

5. Cho RHW, Yeung ZWC, Ho OYM, Lo JFW, Siu AKY, Kwan WMY, To ZWH, Chan AWH, Chan BYT, Fung KSC, Abdullah V, Tong MCF, Ku PKM (2020) Pearls of experience for safe and efficient hospital practices in otorhinolaryngology-head and neck surgery in Hong Kong during the 2019 novel coronavirus disease (COVID-19) pandemic. J Otolaryngol-Head Neck Surg 49:30. https://doi.org/10.1186/s40463-020-00427-4

6. WHO Director-General's opening remarks at the media briefing on COVID-19-11 March 2020 (n.d.). https://www.who.int/ $\mathrm{dg} /$ speeches/detail/who-director-general-s-opening-remarks-atthe-media-briefing-on-covid-19-11-march-2020. Accessed 28 June 2020

7. Zou L, Ruan F, Huang M, Liang L, Huang H, Hong Z, Yu J, Kang M, Song Y, Xia J, Guo Q, Song T, He J, Yen HL, Peiris M, 
Wu J (2020) SARS-CoV-2 viral load in upper respiratory specimens of infected patients. N Engl J Med 382:1177-1179. https://doi.org/10.1056/NEJMc2001737

8. Wang W, Xu Y, Gao R, Lu R, Han K, Wu G, Tan W (2020) Detection of SARS-CoV-2 in different types of clinical specimens. JAMA—J Am Med Assoc 323:1843-1844. https://doi.org/ 10.1001/jama.2020.3786

9. Soetikno R, Teoh AYB, Kaltenbach T, Lau JYW, Asokkumar R, Cabral-Prodigalidad P, Shergill A (2020) Considerations in performing endoscopy during the COVID-19 pandemic. Gastrointest Endosc 92:176. https://doi.org/10.1016/j.gie.2020.03.3758

10. Luo M, Cao S, Wei L, Tang R, Hong S, Liu R, Wang Y (2020) Precautions for intubating patients with COVID-19. Anesthesiology 132:1616-1618. https://doi.org/10.1097/ALN.0000 000000003288

11. Gupta S, Shahidi N, Gilroy N, Rex DK, Burgess NG, Bourke MJ (2020) Proposal for the return to routine endoscopy during the COVID-19 pandemic. Gastrointest Endosc. https://doi.org/ 10.1016/j.gie.2020.04.050

12. Thamboo A, Lea J, Sommer DD, Sowerby L, Abdalkhani A, Diamond C, Ham J, Heffernan A, Cai Long M, Phulka J, Wu YQ, Yeung P, Lammers M (2020) Clinical evidence based review and recommendations of aerosol generating medical procedures in otolaryngology - head and neck surgery during the COVID-19 pandemic. J Otolaryngol-Head Neck Surg. https://doi.org/ 10.1186/s40463-020-00425-6

13. Armstrong D, Barkun A, Bridges R, Carter R, De Gara C, Dubé C, Enns R, Hollingworth R, MacIntosh D, Borgaonkar M, Forget S, Leontiadis G, Meddings J, Cotton P, Kuipers EJ, Valori R (2012) Canadian association of gastroenterology consensus guidelines on safety and quality indicators in endoscopy. Can J Gastroenterol 26:17-31. https://doi.org/10.1155/2012/173739

14. Armellini E, Repici A, Alvisi C, Dinelli M, Gambitta P, Manes G, Mutignani M, Orlando S, Radaelli F, Salerno R, Venezia G, Verna C, Penagini R, Pace F (2020) Analysis of patients attitude to undergo urgent endoscopic procedures during COVID-19 outbreak in Italy. Dig Liver Dis. https://doi.org/10.1016/ j.dld.2020.05.015

15. De Luca P, Scarpa A, Ralli M, De Vincentiis M, Cassandro E, Chiarella G, Cassandro C (2020) Nasal, pharyngeal and laryngeal endoscopy procedures during COVID-19 pandemic: available recommendations from national and international societies. Eur Arch Oto-Rhino-Laryngol 277:2151-2153. https://doi.org/ 10.1007/s00405-020-06028-1

16. Rameau A, Young VVN, Amin MR, Sulica L (2020) Flexible laryngoscopy and COVID-19. Otolaryngol-Head Neck Surg (United States) 162:813-815. https://doi.org/10.1177/ 0194599820921395

17. Gastrointestinal Endoscopy During the COVID-19 Pandemic: An Updated Review of Guidelines and Statements from International and National Societies - PubMed (n.d.) https://pubmed.ncbi. nlm.nih.gov/32268135/. Accessed 26 June 2020

18. Cohen LB, Ladas SD, Vargo JJ, Paspatis GA, Bjorkman DJ, Van Der Linden P, Axon ATR, Axon AE, Bamias G, Despott E, Dinis-Ribeiro M, Fassoulaki A, Hofmann N, Karagiannis JA, Karamanolis D, Maurer W, O'Connor A, Paraskeva K, Schreiber F, Triantafyllou K, Viazis N, Vlachogiannakos J (2010) Sedation in digestive endoscopy: the Athens international position statements. Aliment Pharmacol Ther 32:425-442. https://doi.org/ 10.1111/j.1365-2036.2010.04352.x

19. Sundaram E, Manickavasagam K, Goel R, Subhash K, Govindaraj K, Bhimanakunte K, DeSarkar S, Borgoankar V, Rathod V (2020) Indian Association of Gastrointestinal Endo Surgeons COVID-19 endoscopy recommendations. J Minim Access Surg 16:201. https://doi.org/10.4103/jmas.jmas_92_20
20. Ang TL, Li JW, Vu CKF, Ho GH, Chang JPE, Chong CH, Chua TS, Ong DEH, Yip BCH, Gwee KA (2020) Chapter of gastroenterologists professional guidance on risk mitigation for gastrointestinal endoscopy during COVID-19 pandemic in Singapore. Singapore Med J. https://doi.org/10.11622/smedj. 2020050

21. Castro Filho EC, Castro R, Fernandes FF, Pereira G, Perazzo H (2020) Gastrointestinal endoscopy during the COVID-19 pandemic: an updated review of guidelines and statements from international and national societies. Gastrointest Endosc. https://doi.org/10.1016/j.gie.2020.03.3854

22. Lui RN, Wong SH, Sánchez-Luna SA, Pellino G, Bollipo S, Wong M, Chiu PWY, Sung JJY (2019) Overview of guidance for endoscopy during the coronavirus disease 2019 pandemic. J Gastroenterol Hepatol 35(2020):749-759. https://doi.org/ 10.1111/jgh. 15053

23. Phelan AL, Katz R, Gostin LO (2020) The novel coronavirus originating in Wuhan, China: challenges for global health governance. JAMA-J Am Med Assoc 323:709-710. https:// doi.org/10.1001/jama.2020.1097

24. Zhou F, Yu T, Du R, Fan G, Liu Y, Liu Z, Xiang J, Wang Y, Song B, Gu X, Guan L, Wei Y, Li H, Wu X, Xu J, Tu S, Zhang Y, Chen H, Cao B (2020) Clinical course and risk factors for mortality of adult inpatients with COVID-19 in Wuhan, China: a retrospective cohort study. Lancet 395:1054-1062. https:// doi.org/10.1016/S0140-6736(20)30566-3

25. Balakrishnan K, Schechtman S, Hogikyan ND, Teoh AYB, McGrath B, Brenner MJ (2020) COVID-19 pandemic: What every otolaryngologist-head and neck surgeon needs to know for safe airway management. Otolaryngol—Head Neck Surg (United States) 162:804-808. https://doi.org/10.1177/0194599820919751

26. Item 1000/25 | Repositorio nacional (n.d.). https://covid-19. conacyt.mx/jspui/handle/1000/25. Accessed 7 July 2020

27. Krajewska J, Krajewski W, Zub K, Zatoński T (2020) COVID-19 in otolaryngologist practice: a review of current knowledge. Eur Arch Oto-Rhino-Laryngol 277:1885-1897. https://doi.org/ 10.1007/s00405-020-05968-y

28. Thompson CC, Shen L, Lee LS (2020) COVID-19 in endoscopy: Time to do more? Gastrointest Endosc. https://doi.org/10.1016/ j.gie.2020.03.3848

29. Hall D, Steel A, Heij R, Eley A, Young P (2020) Videolaryngoscopy increases 'mouth-to-mouth' distance compared with direct laryngoscopy. Anaesthesia 75:822-823. https://doi.org/ 10.1111/anae. 15047

30. Francom CR, Javia LR, Wolter NE, Lee GS, Wine T, Morrissey T, Papsin BC, Peyton JM, Matava CT, Volk MS, Prager JD, Propst EJ (2020) Pediatric laryngoscopy and bronchoscopy during the COVID-19 pandemic: a four-center collaborative protocol to improve safety with perioperative management strategies and creation of a surgical tent with disposable drapes. Int J Pediatr Otorhinolaryngol 134:110059. https://doi.org/10.1016/j.ijporl. 2020.110059

31. Pollaers K, Herbert H, Vijayasekaran S (2020) Pediatric Microlaryngoscopy and Bronchoscopy in the COVID-19 Era. JAMA Otolaryngol-Head Neck Surg. https://doi.org/10.1001/ jamaoto.2020.1191

32. Singh N, Bhaskar Rao P, Nitasha Mishra F Video laryngoscopy in COVID-19 patients: a word of caution (n.d.). https:// doi.org/10.1007/s12630-020-01591-x 
33. EBSCOhost | 82583286 | Pain and discomfort during flexible nasolaryngoscopy: a randomized, controlled trial assessing the efficacy of oral mouthwash and topical Lidocaine. (n.d.). https://web.a.ebscohost.com/abstract?direct $=$ true\&profile $=$ ehost\&scope $=$ site \&authtype $=$ crawler\&jrnl $=07077270 \& \mathrm{AN}$ $=82583286 \& \mathrm{~h}=\mathrm{Bb} 6 \mathrm{aOJ} 28 \mathrm{OyZjO} 2 \mathrm{EbY} 3 \mathrm{nkblAbQWms} \% 2 \mathrm{Fk}$ eBiHASefFTq6Rz3rRigkJtH1uMt\%2BAPFtohsRJdvvw6w2DKe CmZ0A4A1A\%3D\%3D\&crl = c\&resultNs = AdminWebAuth $\&$ resultLocal $=$ ErrCrlNotAuth\&crlhashurl $=$ login.. spx $\% 3$ Fdirect \%3Dtrue\%26profile\%3Dehost\%26scope\%3Dsite\%26authtype\% 3Dcrawler\%26jrn1\%3D07077270\%26AN\%3D82583286. Accessed 7 July 2020

34. Tonna JE, DeBlieux PMC (2017) Awake laryngoscopy in the emergency department. J Emerg Med 52:324-331. https:// doi.org/10.1016/j.jemermed.2016.11.013

35. Rosenstock CV, Thøgersen B, Afshari A, Christensen AL, Eriksen C, Gätke MR (2012) Awake fiberoptic or awake video laryngoscopic tracheal intubation in patients with anticipated difficult airway management: a randomized clinical trial. Anesthesiology 116:1210-1216. https://doi.org/10.1097/ALN. 0b013e318254d085

36. Eggers M, Eickmann M, Zorn J (2015) Rapid and effective virucidal activity of povidone-iodine products against Middle East Respiratory Syndrome Coronavirus (MERS-CoV) and Modified Vaccinia Virus Ankara (MVA). Infect Dis Ther 4:491-501. https://doi.org/10.1007/s40121-015-0091-9

37. Saknimit M, Inatsuki I, Sugiyama Y, Yagami K (1988) Virucidal efficacy of physico-chemical treatments against corona viruses and parvo viruses of laboratory animals. Jikken Dobutsu 37:341-345. https://doi.org/10.1538/expanim1978.37.3_341

38. Yen MY, Lu YC, Huang PH, Chen CM, Chen YC, Lin YE (2010) Quantitative evaluation of infection control models in the prevention of nosocomial transmission of SARS virus to healthcare workers: implication to nosocomial viral infection control for healthcare workers. Scand J Infect Dis 42:510-515. https:// doi.org/10.3109/00365540903582400

39. Kampf G, Todt D, Pfaender S, Steinmann E (2020) Persistence of corona viruses on inanimate surfaces and their inactivation with biocidal agents. J Hosp Infect 104:246-251. https://doi.org/ 10.1016/j.jhin.2020.01.022

40. Abramowicz JS, Basseal JM (2020) World federation for ultrasound in medicine and biology position statement: how to perform a safe ultrasound examination and clean equipment in the context of COVID-19. Ultrasound Med Biol. https:// doi.org/10.1016/j.ultrasmedbio.2020.03.033

41. Heinzerling A, Stuckey MJ, Scheuer T, Xu K, Perkins KM, Resseger H, Magill S, Verani JR, Jain S, Acosta M, Epson E (2020) Transmission of COVID-19 to health care personnel during exposures to a hospitalized patient-Solano County, California, February 2020. Morb Mortal Wkly Rep 69:472-476. https://doi.org/10.15585/MMWR.MM6915E5

42. Rutala WA, Weber DJ (2014) Disinfection, sterilization, and control of hospital waste. In: Mand. Douglas, Bennett's Princ. Pract. Infect. Dis., Elsevier Inc., pp 3294-3309.e1. https://doi.org/10.1016/B978-1-4557-4801-3.00301-5

43. Ten key guidance points: Aerosol Generating Procedures (AGPs) within the ENT clinic, n.d

44. Mendes GCC, Brandão TRS, Silva CLM (2007) Ethylene oxide sterilization of medical devices: a review. Am J Infect Control 35:574-581. https://doi.org/10.1016/j.ajic.2006.10.014

Publisher's Note Springer Nature remains neutral with regard to jurisdictional claims in published maps and institutional affiliations. 